\title{
DUA TANI: (Re)evolving Identities of Pacific Islanders
}

\begin{abstract}
Colonization, modernity and migration have impacted indigenous peoples globally. Of particular interest, is how identity formation of indigenous peoples are affected through these events. This article explores the life narratives of 20 Pacific Islanders in Brisbane, Australia, and their perceptions of identity. Through talanoa (culturally appropriate conversation) a deeper understanding of how Pacific Island people navigate, use, build and (re)shape their identities was established. The findings showed that although all the participants acknowledged the effects of colonialism, migration and western social expectations, their Pacific culturalism was central to their identity formation. Furthermore, participants expressed that without an understanding of who they were as Pacific Islanders, they would inevitably internalize negative perceptions. Interestingly, all the participants in the study also spoke of the complex intersections and hybrid notions of identity they

Elijah Lemusuifeauaali'i (Matāutu Lefaga, Malie, Eva, Ngāti Porou, Te Whanau a Apanui \& Te Whanau a Maruhaeremuri) is an undergraduate student majoring in Pacific Island Studies and Cultural Anthropology at Brigham Young University of Hawaii.

Dion Enari (Lepa, Malaela, Safune, Vaiala, Nofoali'i) is a Samoan PhD candidate in the Faculty of Society and Design, Bond University, Gold Coast, Australia.
\end{abstract}


embodied, as opposed to a traditional single representation of self. This study provides a snapshot of an ever (re)evolving Pacific story, still being written.

\section{Foreword}

The title of this work and documentary film is entitled 'DUA TANI: Re-evolving Identities'. The words 'DUA TANI' are derived from the Fijian language of the Bauan dialect, $\mathrm{Na}$ iVosa Vakaviti or $\mathrm{Na}$ iVosa Vakabau. It is loosely translated as new, different, extraordinary or other; in either a positive or an admirable context. For example, "Sa, dua tani sara ga na keke oqo" meaning, "Wow! This cake is something else". This paper uses the term 'DUA TANI' as a metaphorical title to help display the primary message of new, hybrid and re-evolving Pacific identities.

\section{Acknowledgements}

To each of the participants, who played such a vital role in this journey, I express my deepest gratitude and thanks for your willingness to not only assist me, but to offer your wisdom and assistance to those of our next generation Pacific Islanders. For many of you are the connecting links and pioneers who travelled the seas and skies to reach this new homeland of milk and honey, Australia. Thank you for being a part of this journey with me.

To my good and close friend Quincy Tahiata, I express my thanks and sincerest appreciation for you and your continuous will to give of your time, talents, gas, money, home and family to ensure that this initial personal project was a success. Without your support and encouragement, whether from the sideline, the back or front, I would not have been able to be so bold and 
ambitious to take on such a task despite all my talents. It is people like you, who change the world. Mauru'uru roa!

To my new-found relative Mark Paongo of Mark Paongo Films, Brisbane. Fakamālō atu ki a koe masi'i, mālō 'aupito mo e tokoni mai ki he ngaue mamafa ko eni pea ho anga'ofa, anga'lelei pea he tauhi lelei ki he feiloaki kitaua. Mālō lahi toko. With your videography skills and talents, this project was made possible and was enabled to go from mere thought to a living reality. Your dedication to family via your social skills and work ethics are nothing short of inspirational.

Finally, I express my gratitude to my grandfather Grahame, mother Anahera, father Siota and my extended relations who all played a part in supporting me through this project. I am grateful for your constant love, encouragement and belief that continues to flow and act as humble nourishment to keep pushing forward. I hope that this work will be able to teach and offer somewhat of a guideline to those of my relations that like me, struggled to navigate their way through personal and cultural identity. I love you all. 


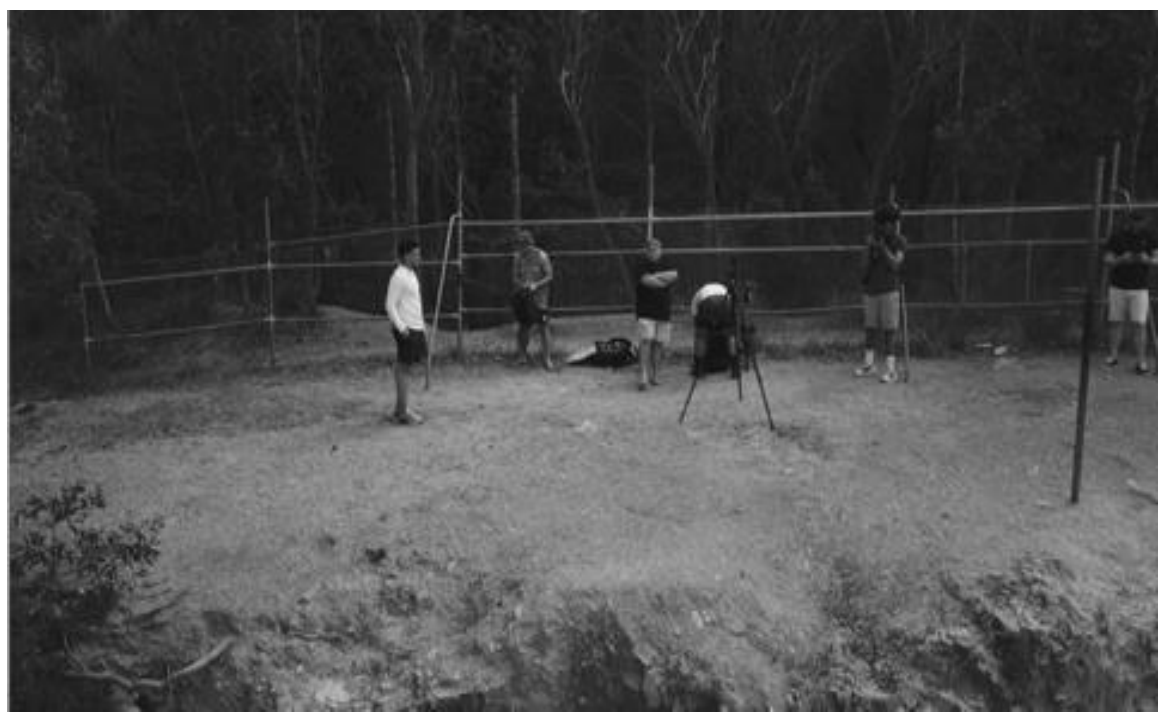

Figure 1: Last day of interviews in Logan, Brisbane (September, 2020)

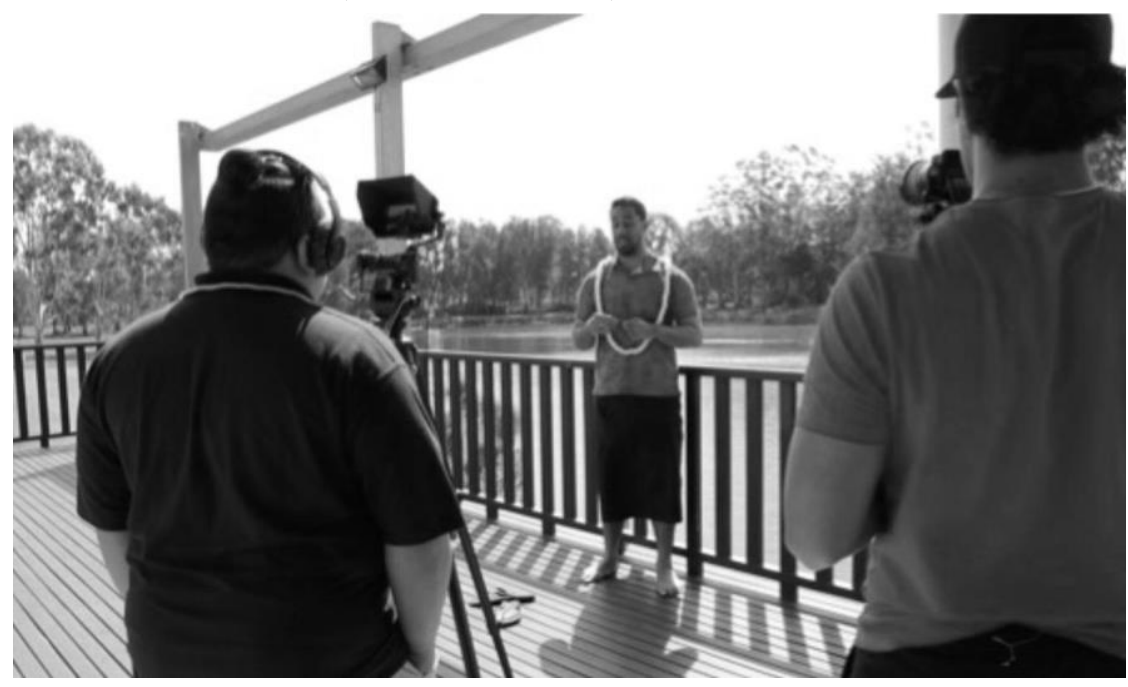

Figure 2: Live recorded interview with $\mathrm{PhD}$ candidate, Lefaoali'i Dion Enari (August 2020) 


\section{Introduction}

Pacific Islanders have navigated the western system by excelling in such areas as government leadership, land management, national infrastructure, international relations, business ethic and most prominently, contemporary influences in social culture. Consequently, many of these attributes have contributed to a shift in the portrayal of Pacific Islanders and is a contributing factor to (re)evolving identity formation. We commonly associate identity with an understanding of race and ethnicity, as an extension of the place a person or group originates from (Enari \& Fa'aea, 2020). As Pacific people we believe that identity formation must also draw upon the concept of space and time (Enari \& Faleolo, 2020). As the famed Marvel Avenger, Thor the God of Thunder quotes of his homeland "Asgard is not a place, it's a people", this same quote is applicable and relative to the people of the Pacific in how our identities experience change, via our migrational movements and spatial or geographic experiences (Tengan, 2008). To contextualize this quote to Pacific Islanders “The Polynesian is not a place, it's a people" and as that people move, experience, develop and progress, so too does the definitive fluidity of a Pacific Islander.

There have been numerous narratives that have sought to define and provide insight to the Pacific Islander. Additionally, further exploring what it means to be part of a vast oceanic empire. According to Kupo (2010) Hawaiians, have been widely portrayed with "Images of women in grass skirts dancing in firelight, men in loincloths twirling fire poles or carrying food from the Imu [in-ground oven], and depictions of the luau are associated with and create the archetypes of the 
indigenous people of Hawai'i. Descriptions such as exotic, welcoming, hospitable, and entertaining are used to depict Native Hawaiians".

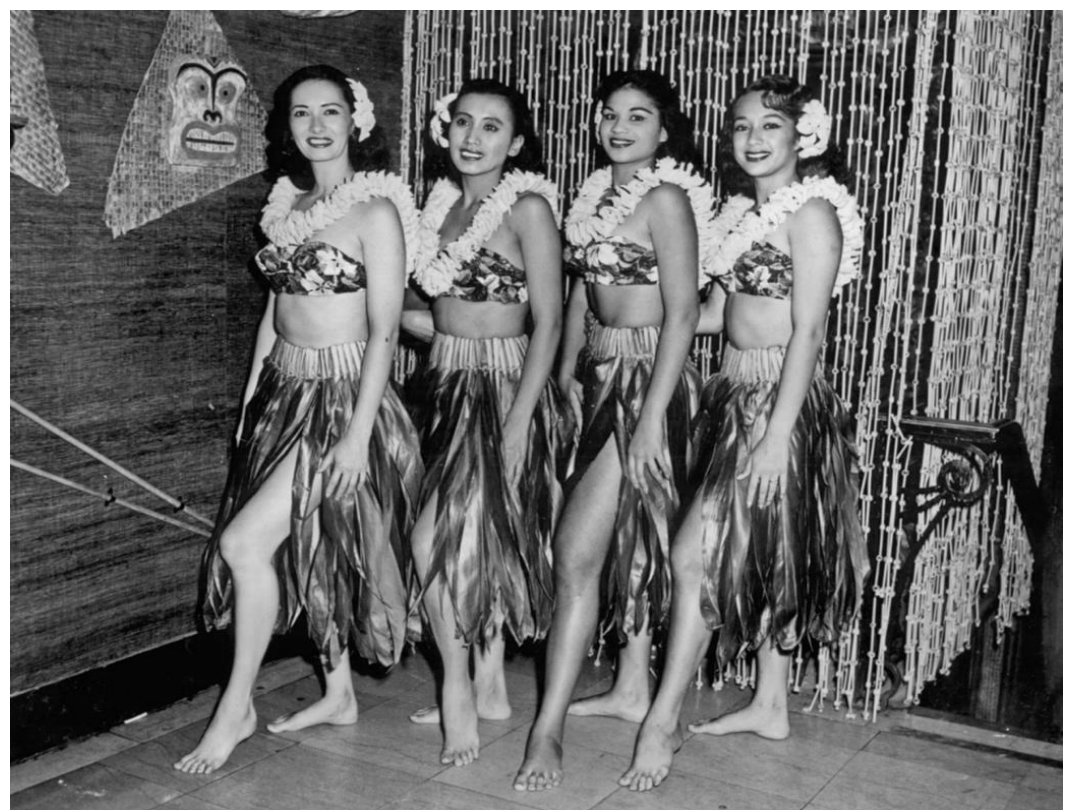

Figure 3: Women of Hapa Haole Hula. (2015) 


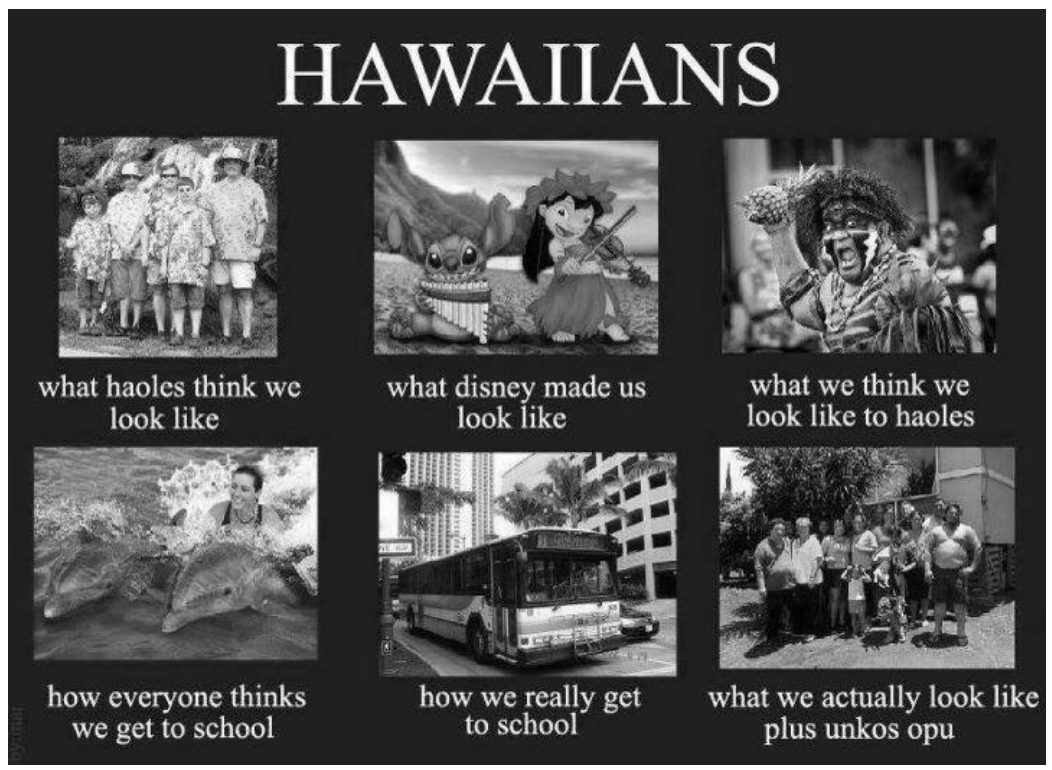

Figure 4: HAWAII. (2012)

In spite of these varied and vain representations of Hawaii and Hawaiians, much of the Western discourse also perceives other Pacific cultures similarly. Portraying them as objects of entertainment, to use their cultural practice as means to support and verify selected social contexts. As study participant Quincy Tahiata explains in the following statement via face to face interview.

"Bro, can you do us a Haka?", I asked him "Why? Who and what is it for? He said back, "One of the boys wants to do one because his brother graduated high school". I sat there shaking my head, they expect me to conjure up some enchanting cultural performance at the drop of a hat. Never mind the fact I hold no blood or social connection to the person or that he himself is not Māori. All of that is disregarded because their main objective is 
to simply fill their void with the feeling of captivation and excitement, because they lack what I don't. A culture.

- Tahiata, Quincy. (2020) Survey Participant.

Sovereignty representation is important, but sadly, many Pacific Islanders and other indigenous groups fall victim to the definition and perceptions of foreign thought. Traditionally, the power to define and redefine has continuously remained with the colonizer, regardless of tribe, continent, island or nation, the same vain ambition is carried throughout in a pursuit to only validate the preliminary notions of western thought deeming him of higher stock and greater civility than his lower-class native counterpart (Enari \& Matapo, 2020; Enari \& Matapo, 2021). The early exploration of Europeans travelling during the Enlightenment era in search of new lands and civilizations, showed a degrading portrayal of Pacific people and cultures. From all manner of early scholarship, including philosophers such as, Jean Jacques Rousseau when he said, "there was no education or progress; the generation multiplied unproductively, and because each began anew from the same point, centuries passed by in all the crudeness of the earliest ages; the species was already old, and man remained ever a child" (Lansdown, 2006).

For the Tahitians, the depictions of their race became strongly connected to representation of other Pacific Islanders and how the West viewed much of the other parts of the Oceanic region. As Kahananui mentions, Tahitian women were "Dehumanized women to the point that they were seen to exist only for men's pleasure." (Kahananui, 2002). The European perception of indigenous Tahitian [Pacific] females can be likened to 
how he would view land. As a tangible prize to be won, a possession to be conquered or attained to only justify his efforts and sins in and of his loyalty to the noble cause at hand, the expansion and exploitation of colonialism. It is clear that the exploitation of Tahitian [Pacific] women, their identities and portrayals was without question, romanticized, fantasized, patronized and can still be seen in and around the Pacific.

See we were perceived as objects, considered uncivilized; labelled without ability and yet somehow needed to be immunized. Our state of being was not up to par, nor did it meet the standard, we were exotic animals sadly confined and stranded. To an island home so small and primitive, yet they needed us to prove their initiative. Noble Savages they said, mysterious in our capacity; fortunately, able to fulfill both assumption \& vain fantasy. TANI'.

Pacific people, however, were not blind to the lustfulness and cunning ways of the West, particularly towards native women. As captain of the H.M.S Dolphin ship George Robertson recorded "Several Tahitian men noticed his crew 'feasting their eyes' on several attractive young girls. The Tahitian men consequently motioned the crew to come over to pick out their favorite girl in exchange for a nail". (Kahananui, 2002). This record of Pacific men and women via western discourse further emulates the concept of the noble savage. The noble savage, being a savage by nature and yet is noble also knowing not the evils and ills of the wide world to which of course are common and apparent to the Westerner (Murray, 1933). Yet, in this example we see that the reason for female 
neglect on the part of the Tahitian man is due to the commodities westerners brought and introduced, allowing a tempting desire to be flaunted in its display, without realizing corruption was to enter. While such imagery is oppressive, unjust and biased, it is important to acknowledge past representations of Pacific humanity by both Pacific and non-Pacific scholarship, in an endeavoring effort to assure moving forward we know how to better re-define and define ourselves, via the empowerment of our own narratives. "The Hawaiian [Pacific Islander] stands firmly in the present, with his back to the future, and his eyes fixed upon the past, seeking historical answers for present-day dilemmas" (Kame'eleihiwa, 1992)

While many natives strive to maintain the traditional values and indigenous practices that essentially contribute to their identity, there are a multitude of other realities that demonstrate a shift in cultural identity.

\begin{abstract}
We are essentially different now. I mean we're still very cultural and try to always keep our culture alive through dances and songs and all, but I mean if you compare me to my grandma, we're totally different. I mean, yeah, we're both Tongan but I mean we live a different experience of being Tongan.
\end{abstract}

- Tomu, Melissa. (2020) Survey Participant.

\title{
The Role of Tā and Vā
}

In the Sāmoan and Tongan languages, Tā means 'to beat, to mark, to form or perform". In a temporal sense, Tā serves as a marker within and of time, marking the everyday actions and events that occur. For instance, 'Tā 
le pese' in Samoan translates to 'play the song'. "Tātou ō" or "Tā ō" means 'Let us go'. Tā serves as a time stamp, indicating the required moments to perform an action. It essentially refers to time and as such acts as a measurement of the happenings that occur within it (Ka'ili, 2017). Vā on the other hand signifies space (Enari $\&$ Matapo, 2021). "Important to the Samoan view of reality is the concept of Vā or Wā in Māori. Va is the space between, the betweenness, not empty space, not space that separates, but space that relates. ... A well-known Samoan expression is 'la teu le va'-cherish, nurse, care for the va, the relationships. This is crucial in communal cultures that value group unity more than individualism, that perceive [of things] in terms of group, in terms of va, relationships". (Lilomaiava-Doktor, 2009)

Both Tā and Vā inextricably co-exist and cannot be separated as all facets of Pacific being are connected to and by them. Irrespective of migration and distance, they remain alive via the social obligations that coincide with and within Pacific culture(s). To be Sāmoan is to 'tausi le vā o le a'iga', to care or nurture the space between familial relations (Enari \& Fa'aea, 2020), whether in the intimacy of a family or village environment or the longevity in distant relationships stretched between countries. It is a necessary segment that emphatically allows Samoan culture to remain reciprocally alive. "Samoan migrants do not live between two places with no single place to call home; rather, they remain firmly rooted in their identification with their place of origin. These blood and body links are internally related and functionally interdependent." (Lilomaiava-Doktor, 2009)

As Pacific Islanders move between and throughout the timeline, they automatically stretch and expand the 
relationships of time (Tā) and space (Vā). By migrating abroad from Pacific homelands, they further shape the boundaries of Vā and what it means to nurture them (Enari \& Faleolo, 2020). For example, in traditional practice, it was common to offer, bring and exchange culturally appropriate gifts when attending a funeral, wedding, title bestowal and other cultural ceremonies. Such gifts or objects included fine mats (ie toga), crops (talo, fa'i, ufi, ulu etc.), animals from land and sea (pua'a, i'a, povi etc.), as well as decorative adornments for the body such as various types of necklace (LilomaiavaDoktor, 2009). In these instances, gifts demonstrated a social group's respect and character, while simultaneously actively nurturing and appreciating the relationship that is shared between the parties involved. Now, as Pacific Islanders travel abroad and establish new homelands, other means of exchange or nurturing take on new forms and shapes. Monetary donations commonly replace gifts and decorative adornment, soda replaces coconuts, industrial made materials and pre-packaged foods replace livestock and crops etc. Understandably, as culture evolves, such changes also impact forms of cultural practice, allowing shifts and re-definitions in identity. While such changes have occurred due to changing times, there is much concern for Pacific Island people, cultures and identities. Through new experiences, exposure and open opportunity to the wondrous infinite options of the West, what is to become of the Pacific people and their seemingly continuously abstruse identities? Are we to continue being told our identity via the sports institutions that unceasingly enlist young Pacific men into the realms of rugby and football, or assume the normality to living life in low economic 
neighborhoods and be subject to low income paying careers? Are we to assimilate to Western life, ignoring, forgetting and neglecting our forebears having no real connection or grasp of past and present? Such challenges cause, as Osorio explains, "Huikau" (confusion) "confusion, over what our choices are and what they mean that is threatening our nation" (Osorio, 2006).

\section{Methodology}

Research was conducted in Brisbane, Australia carried over a 3 month period from August 2020 to October 2020, both recorded in written and video format. Among the 20 people who participated in this study, both online and in face to face interviews, 10 participants were video recorded with their responses formulated into a documentary film while the remaining 10 answered survey question sheets. These questions for both the video recorded interviews and survey sheets were the same. Each interviewee was asked a series of questions formulated from the primary questions below:

1. Define in your own words the meaning of "Identity".

2. How is identity relative to both the individual and collective?

3. What changes have you seen in how Pacific people interpret identity? With added emphasis to biracial/multi-ethnic individuals and families that have come as a result to intercultural marriage and/ or migration.

4. In your opinion/ understanding, is colonialism still ongoing? And how has it affected and impacted the Pacific identity? 
5. Varying groups argue that motives behind common Pacific stereotypes are due to a lacking comprehension of self-identity and cultural values/ principles. Would you agree/disagree?

6. Why should we as Pacific people in the diaspora, emphasize the need for indigenous knowledge both in the traditional and contemporary context?

\section{Results}

After reviewing the interviews and written responses of each participant involved in the study, data results showed three contributing factors associated with the reevolving Pacific identity. Additionally, study participants expressed that they were each products of colonization and westernization as they migrated abroad for further opportunities, both for self and family. These three identified factors were, intercultural marriage, migration and indirect colonization. However, in the following discussion, I address solely the topics of intercultural marriage and migration, as the third will be addressed in later account of its own, exploring indirect colonization in further depth.

\section{Discussion}

\section{Intercultural Marriage}

Throughout Pacific history, there are many accounts of intercultural marriage. King Taufa'ahau Tupou I of Tonga and other relatives to the king shared multiple bloodlines to the royal family lineages of Samoa (Spurway, 2015). Taufa'ahau's infamous cousin "Na Tui Lau", The King of Lau or as he was later named Ma'afu Fisi, was himself both Tongan and Samoan as he was a descendent of the Tu'i Kanokupolu line, which is a line with direct links to 
the island of Upolu, Samoa (Spurway, 2015). Much Pacific oratory also speaks of intermarriage between islands, with common tales of the acquisition of land, power and forms of cultural exchange (Gunson, 1997). Whilst a majority of participants in this study shared multiple Pacific blood relations, some also only identified with one nationality, for example some only claimed individual ethnic ties to Samoan, Tongan, Māori, Niuean and Fijian. Interestingly however, all the study participants who only claimed one nationality had children, grandchildren, cousins and other relatives that identified with multiple ethnicities.

My father is Tongan, and my mom is Hawaiian-Filipino. On any given day, probably Sunday we could be preparing Filipino food, listening to Hawaiian music, after just coming from a Tongan church program. My identity has always been a part of who I am.

- $\quad$ Funaki, Ulise. (2020) Video Recorded Participant.

For those Pacific Islanders who are born with duality or multi Pacific ethnicities, their understanding and interpretation of personal and Pacific identity is commonly contrasted. While they remain one ethnicity, they also pertain to another or others. The Pacific experience is varied and therefore provides an outlook on what it means to be European whilst also being Hawaiian /Fijian, Tongan/ Niuean/ Māori, Tongan /Samoan or Chinese, Samoan and German etc. As one participant stated "I am Māori but I'm also Tahitian and therefore I'm not just one, but I am two, and so I not only have responsibilities to one part of myself but both. There's a balance that needs to take place, but that balance comes 
from first acknowledging the realities of your past and present self" (Tahiata, 2020) Personal survey response). Intercultural marriage allows the opportunity for cultures to expand and go beyond horizons, to see and understand from another's view, enabling the potential for greater unity, harmony and shared mutual respect of one another's similarities and differences. For Pacific Islanders, while many facets of culture are coincidentally similar, it still provides the opportunity for greater learning of others and self. Rather than perceiving an individual as confused and mixed, labelling them with such negative racial titles such as 'runny' or 'coconut', such uniqueness creates a sense of hybridity. By possessing multiple cultural backgrounds, an individual possesses multiple histories, lineages, genealogies, stories, cultural customs, practices and knowledge, talents, natural skills, languages, treasured wisdoms etc. As one lives today, no matter how ethnically diverse, he or she is able to access those doors where only few can venture. "I am one, but I am two. Those before me are me, as those to come are you." (Lemusuifeauaali'i, 2020, Spoken Word Piece 'Dua Tani')

\section{Migration}

My parents migrated from Niuē to New Zealand. It's easy to migrate because Niue comes under the New Zealand government. In my later years, we moved to Australia, because that was the next step in providing a better future for us and the generations to come.

- Liufau, Cressida. (2020) Survey Participant.

Pacific Islanders have made numberless journeys, migrating anciently throughout the Pacific Islands and 
beyond. Even still today they migrate to countries in pursuits that broaden the initial scope of ancient migration. As they traverse these spaces of vā through tā and malaga (Lilomaiava-Doktor, 2009), their affixed identities and those of their posterities undergo the inevitable identity shift, differentiating them slightly from ancestral kin. While for the most part, still rooted, founded in their island origins, the building and adding thereof on top of these foundations presents a newness in representational comparison. We compare this change to that of different species of animal. For example, the tall Red Kangaroo of Australia makes his home in the vast desert shrub lands of inner outback Australia, his relative the Tree Kangaroo, however, makes his home in the treetops of the lush Australian forests (Procter-Gray \& Ganslosser, 1986). Both are still of the same Kangaroo family, yet one differs from the other not only in habitat, size and diet, but the environment they choose to surround themselves in (Carter, 2020).

By living in a foreign country, Pacific Islanders have had to learn new ways of being (Enari \& Rangiwai, 2021). Pacific Islanders in Australia have had to learn colloquial slangs, slurs, phrases and lingo of Australia and local neighborhoods as a means of gaining social acceptance within the Australian social context. While forms of assimilation have the potential to erase or override traditions and cultural practices of newly arrived Pacific Islanders, this is a possible part of integration to Western society. Consciously and unconsciously as Pacific Islanders adapt to western ways of normality, it soon becomes habitual and natural. These avenues provide an additional layer of identity on top of their embedded cultural identities. Although still rooted in origins from 
lives before and lineages of those who made the migrational journey, they're also situated in the new or present that is the reality they currently live. This is particularly evident among third and fourth generation Pacific Islanders in Australia.

For these Islanders, the difference is predominantly unrecognizable knowing nothing other than the Western experience provided to them. While family members strive to ensure a qualitative Pacific experience, to know social and cultural protocols, customs, languages, knowledges and practices, bridging the gaps between tradition and contemporary, identity undoubtably becomes a challenging task. As they remain in a state of here and now, having a lacked relativity to a past identity and origin they neither lived nor experienced. This is where the potential downfall of Pacific hybridity or re-evolution is introduced and reverses hybridity back to singularity. Although the bloodline is obvious to express an individual's racial background, mentally, spiritually and physically features, he or she now faces the challenging task of reconnection, which if not successful navigated can leave an individual in a state of being "Metaphorically drowned" according to Māhina (Māhina, 2017). This is where and why there must be a balance between identities in order to maintain this claim or status of hybridity. In maintaining active relationships with Vā and Tā between identities. Otherwise, if not maintained, sustained or retained, one's hybridity becomes stagnant, unable to continuously develop, separated from his or her inheritance and left to restart.

Like my children for example, they're Aussies. Even though their DNA says Māori, Tahitian and Hawaiian, 
they're Aussies. If we lived in the island and went to the village dances every weekend, spoke our language and that, it would be a different story. But since we live here in Australia, they're experience really is the Australian story.

- Tahiata, Heimana. (2020) Video Recorded Participant.

\section{Conclusion}

In a basic statement, identity is important. It is vital and pivotal to the development of Pacific Islanders as they live, move and migrate through varying times or eras, contexts, contents and spaces (Enari \& Taula, 2021). Via intercultural marriage and other interconnected means of cultural intersection, Pacific Islanders are able to unlock the doors to further learning and studying of self and those around them, in the overall Oceanic realm. By acknowledging the influences of migration, historic colonization and ongoing indirect unconscious colonization as well westernization assimilation, Pacific Islanders undoubtedly undergo diverse and drastic changes that vary according to place, time and individual traits and experiences. Those Pacific Islanders introduce and live this concept of cultural hybridity, as being founded in traditional culture yet living in Western society, being not only one ethnicity but multiple, adopting also the characteristics and traits to their personal identities that come along with diasporic movements to the Western World [In this instance, Australia]. However, the dangers and challenges of hybridity are evident, in that a lack of care and nurturing to the relational spaces that connect one's cultural identity to one's present temporal or societal identity can 
be damaged or lost if not actively performed. As Pacific Islanders nurture these personal relationships of self and seek to fortify themselves in them, keeping an open connection to the past whilst in the present, the future can be successfully charted as they navigate the seas and oceans of their lives, the lives before them and the lives to come (Fa'aea \& Enari, 2021).

"Occasionally looking back to our old displacing habits, we can overcome these shortcomings, wipe the negativity away, and move forward. [In a] symbolic way [of] (re)placement helping us as Native Hawaiians [and Pacific Islanders] to shape and form our cultural identities. There is a culturally based template that is originally shaped and structured around shared ways of knowing and being, but each individual is allowed to work from that pattern to create a unique design." (Fermantez, 2012) Pacific Islanders are among the many indigenous peoples of the world that are able to survive in varying degrees of place and circumstance, from cold Alaska to hot Australia, from the United Kingdom to the United States. Pacific Islanders are without doubt a survival people and have made numerous contributions to the countries in which they inevitably choose to reside, becoming movie and film stars, international singers and artists, national sports legends and Olympic athletes, successful lawyers and members of government, local barbers, restaurant owners and more. Wherever they roam, they make themselves ultimately known. Regardless of early narratives that portray them and us as different, the ability to push forward whilst striving to maintain past and present familial, tribal and cultural connections is adamant. They and we are the living examples of unique hybridity. 


\section{References}

Carter, L. (2020). Red Kangaroo. Australian Museum. https://australian.museum/learn/animals/mammal s/red-kangaroo

Enari, D \& Fa'aea, A. M. (2020) E tumau le fa'avae ae fesuia'i faiga: Pasifika Resilience During COVID-19. Oceania, 90, 75-80.

Enari, D \& Faleolo, R. (2020) Pasifika well-being during the COVID-19 crisis: Samoans and Tongans in Brisbane. Journal of Indigenous Social Development, 110-127.

Enari, D \& Matapo, J. (2020) The Digital Vā: Pasifika education innovation during the Covid-19 pandemic. MAI Journal, 9(4), 7-11

Enari, D \& Matapo, J. (2021) Negotiating the relational vā in the University: A transnational Pasifika standpoint during the Covid-19 pandemic. Journal of Global Indigeneity.

Enari, D \& Rangiwai, B. (2021) Digital innovation and funeral practices: Māori and Samoan perspectives during the COVID-19 pandemic. In Alternative journal (Forthcoming)

Enari, D \& Taula, L. (2021) Tattoo My Mouth: Samoan language survival in Australia. in Alternative Journal (Forthcoming)

Fa'aea, AM \& Enari, D (2021) The Pathway to leadership is through service. Pacific Dynamics: Journal of interdisciplinary research (Forthcoming)

Fermantez, K. (2012) "Re-placing Hawaiian in Dis Place We Call Home”. Jonathan Näpela Center for Hawaiian and Pacific Islands Studies. Hulili: Multidisciplinary Research on Hawaiian Well-Being Vol.8 
Gunson, N. (1997) Great Families of Polynesia: InterIsland Links and Marriage Patterns. The Journal of Pacific History, 32(2), 139-179.

Kauanui, J. K. (2007) Diasporic deracination and "offisland" Hawaiians. The Contemporary Pacific, 19, 138-160.

Kauanui, J. K. (2008) Hawaiian blood: Colonialism and the politics of sovereignty and indigeneity. Durham, NC: Duke University Press.

Kupo, V. Leilani. (2010) "What is Hawaiian? Explorations and Understandings of Native Hawaiian College Women's Identities". Higher Education Ph.D. Dissertations. 34.

Kahananui, K. (2002) “Colonialism's Daughters: Eighteenth- and Nineteenth Century Western Perceptions of Hawaiian Women,".

Kame'eleihiwa, L. (1992) "Native Land Foreign Desires: Pehea lā e pono ai?”

KA'ILI, T, and 'MĀHINA, O. (2017) Marking Indigeneity: The Tongan Art of Sociospatial Relations. University of Arizona Press.

Lansdown, R. (2006) Strangers in the South Seas: The Idea of the Pacific in Western Thought. University of Hawai'i Press.

Lilomaiava-Doktor, S. (2020) Oral Traditions, Cultural Significance of Storytelling, and Samoan Understandings of Place or Fanua. Native American and Indigenous Studies, 7(1), 121-151. doi:10.5749/natiindistudj.7.1.0121

Lilomaiava-Doktor, S. (2009) Beyond "Migration": Samoan Population Movement (Malaga) and the Geography of Social Space (Vā). The Contemporary Pacific, 21(1), 1-32. 
Mahina, 'Ō. (2010) Tā, Vā, and Moana: Temporality, Spatiality, and Indigeneity / by Hufanga 'Okusitino Mahina, 168-202.

Mahina, 'Ō. (2017) Time, Space and Culture: A New TāVā Theory of Moana Anthropology. Pacific Studies, 40 (1/2), 105-132

Murray, E. (1933) The "Noble Savage". The Scientific Monthly, 36(3), 250-257.

Osorio, J. (2001) "What kine Hawaiian are you?": A mo'olelo about nationhood, race, history, and the contemporary sovereignty movement in Hawai'i. The Contemporary Pacific, 13, 359-379.

Osorio, J. (1994) Native Land and Foreign Desires: Pehea Lā E Pono Ai?., vol. 6, no. 1, pp. 233-236.

Osorio, J. (2006) "On Being Hawaiian"

Procter-Gray, E., \& Ganslosser, U. (1986) The Individual Behaviors of Lumholtz's Tree-Kangaroo: Repertoire and Taxonomic Implications. Journal of Mammalogy, 67(2), 343-352. doi:10.2307/1380888

Spurway, J. (2015) “Ma`Afu`Otu`Itonga” Ma`Afu, Prince of Tonga, Chief of Fiji: The Life and Times of Fiji's First Tui Lau, by John Spurway. ANU Press, 2015, pp. 1-28. Tengan, T. (2008) Native men remade: Gender and nation in contemporary Hawaii. Durham, NC: Duke University Press.

\section{Images:}

Figure 4: (2012). Hawaii... Reddit.com. Accessed February 2021. (http://www.redit.com/r/Hawaii/coments/pt8uz/ha waii/)

Figure 3: Volcano Art Center, 2015. Women of Hapa Haole Hula. Accessed February 2021., 
https://volcanoartcenter.org/event/hapa-haolehula-workshop/

\section{[i]Notes}

[i] Each account is special and regarded as sacred knowledge. Each account is personal to that individual, as it is a recount of real and lived events and experiences. The fact that I have been blessed enough to record these stories, share them and use them for the benefit of my own personal study and identity journey for the greater goal of a better Pasifika, is both a special and unforgettable experience.

This small work is dedicated to the next generations of Pacific Islanders who like me, are ethnically mixed, living away from their traditional and cultural homelands and seeking to make sense of the world around them as they learn to navigate the seas of themselves in the vast ocean that is the contemporary and traditional worlds. May this be a help to you and others. 